\title{
Education Majors' Preferences on the Functionalities of E-Learning Platforms in the Context of Blended Learning
}

\author{
https://doi.org/10.3991/ijet.v12i05.6971 \\ Nikolay Tsankov \\ South-West University, Blagoevgrad, Bulgaria \\ ntzankoveswu.bg \\ Ivo Damyanov \\ South-West University, Blagoevgrad, Bulgaria \\ damianoveswu.bg
}

\begin{abstract}
The modern stages of higher education development and the actual training of education majors require systematic use of different electronic forms and platforms of education in combination with the traditional educational methods and approaches which will provide students with essential digital skills and competencies, important for their future professional and personal success. Widespread learning management systems provide a common set of basic functionalities. In this study, an assessment of the preferences of education majors on the main functionalities of the electronic platforms used in the context of blended learning in university education is presented. The results reveal a preference on organizational and informational functionalities and less on communication features.
\end{abstract}

Keywords—digital competence, blended learning, e-learning platform, functionality, preferences, education majors

\section{Introduction}

Some contradictory points, concerning the content and the structure of the digital competence of pedagogy specialists, can be outlined in educational theory and practice. They affect the quality of students' university training and professional readiness. The negative aspects of applying information technologies in university programs can be summarized as follows: (1) lack of understanding and adequate approach toward the specific needs of technical students and engineers and information technologies teachers on one hand, and on the other hand other teachers and specialists in the field of education, who are supposed to use information technologies to improve and facilitate their specific work; (2) underestimation of the principles and the potential of the competence approach in designing and implementing training programs, together with the impossibility to define clearly the fundamental components of each competence; (3) vague concept of teachers' digital competence frame- 
work and its value for their professional profile; (4) unclear conceptual model for design and improvement of educational solutions for digital competence development of pedagogy specialists within their professional training. There is a vast range of platforms for electronic training of education majors that offers a variety of functions and topics and involves different skills, included in the digital competence requirements but specific for teachers' professional environment.

Widespread learning management systems such as Blackboard or Moodle provide a common set of basic functionalities. Extending or adapting these functionalities is more or less dictated by the current trends in information and communication technologies, the social networks and the mobile media. Other functionalities include the legacy from the first steps in the development of learning management systems.

The contemporary requirements to educational environment guarantee a high level of individualization in education based on the construction of pedagogical situations.

Born as an alternative caused by concerns on pure e-learning, blended e-learning has been presented as promising. The realization of blended learning at universities is dependent on the level of motivation and interest on part of the students as its subjects as well as on its potential for information processing within the integration of elements of electronic and traditional education.

Various approaches for transforming traditional courses into online ones were developed and various practices of blending face-to-face with online teaching and learning have given rise to intensive processes of theoretical reflection of these practices in an attempt for them to be conceptualized by existing pedagogical theory or used as a basis for creating new pedagogical paradigms [1].

Due to the growing of blended learning, some researchers have already studied students' expectations from [2] and satisfaction with [3] blended e-learning system environment.

We focus our empirical study on the preferences on basic functionalities of elearning platforms used in the context of blended learning and the interest and motivation of the education majors.

\section{Theoretical Background}

The electronic platforms for education are incredibly flexible and allow adding individual characteristics to the educational process depending on student's personal needs or the aims of the training program. Different electronic platforms and environments offer different options for successful training of big groups and at the same time, they provide individual evaluation and assessment. The communication between instructor and students in the electronic portal happens naturally, in an easy manner, and provides effective feedback on training results. On the one hand, it is an important guideline for the instructor when it comes to selection of adequate training methods and strategies and improvement of the educational interaction. On the other hand, students receive free and easy access to the course content and the assessment tools. They can contact the other students in the group or the instructor himself for further information or help. It is also important to mention the potential of modern 
platforms for electronic teaching and learning to present the educational content in a very attractive and easy-to-understand way. It also allows different combinations, interpretations and adaptations of knowledge and affects students' motivation.

Blended learning is a type of new rather than innovative education, which is supposed to change the structure of educational content. It implies information environment and sources as a prerequisite for turning the educational platform into an algorithmic rather than human space. Through blended learning we economize time, means and efforts.

Blended education is the result of the convergence of two classic learning environments - the traditional face-to-face learning and online training. It is also motivated by the need to increase the availability and flexibility of learning in the context of lifelong learning and the need to increase cost efficiency because universities are looking for ways to use technology to achieve both improvement of the quality of education and reduction of costs. The search for opportunities to fully design and implement blended education requires systematization of several of its main models, which play the role of conceptual frameworks. They enable its operationalization and technological realization in practice. Although the "patterns are abstract in their nature, they facilitate effective learning, which requires a specific understanding of the needs of learners, the educational content, the target groups and the organizational conditions and environment" [4].

Blended education does not provide the whole range of options for its implementation, but represents a good basis for defining the features in accordance with the objectives, resources and opportunities for its practical implementation. In the context of these, the realization of blended education at universities seems to be highly dependent on the level of motivation and interest on part of the students as its subjects as well as on its potential for information processing within the integration of elements of electronic and traditional education.

This research aims at searching and finding more variegated opportunities to integrate and adapt electronic learning environments to traditional university training of education majors as a way to improve the quality of their achievements and to maintain high motivation for learning and success. A model of mixed - electronic and traditional training has been created and implemented.

The application of this model in the university training of education majors provides a further opportunity to enrich their digital competence.

Digital competence, defined as one of the eight key competences for lifelong learning includes "the confident and critical use of information society technologies for work, leisure and communication" [5]. Digital competence implies connectivity with the skills to use digital technologies that allow teaching professionals to work with modern information and communication technology, computers, software applications and databases, helping them to realize their ideas and objectives in the context of their work. It is important for education majors to have the ability to search, collect and process information and approach it critically and systematically as well as the skills to use the design tools for media information and the capacity to access, search and use Internet-based services, especially in the context of their future activities and opportunities for continuous professional qualification. 
All this is successfully assisted during their university education through the techniques of blended learning and targeted implementation of electronic platforms in it.

\section{Design of the Empirical Study and Analysis of the Results}

The focus of the presented study is related to the survey of the students' preferences on basic functionalities of electronic platforms used in the context of the implementation of blended learning in university education. This mainly operational level of attitude is directly related to the interest and motivation of students and their adequate involvement in the organization and implementation of their training in specific subjects, using the options for integration of traditional and electronic forms.

The paper studies the functionality of e-learning platforms in the context of blended learning (traditional and electronic) of education majors.

The aim of the study is to pinpoint the students' preferences on the functionality of a particular e-learning platform and motivation in the course of the implementation of blended learning.

The tools for conducting the empirical study include a survey for evaluating the level of motivation and a Questionnaire for the preferences of students on basic functionalities of Blackboard Learn LMS platform.

The survey for assessment of the level of motivation consists of: Introduction with guidelines for assessing and completing the survey, which contains 42 statements with answers on a 7-point grading scale in which the answers comply with a certain sequence. The questionnaire was developed by V. K. Gerbachevski [6] in order to identify the components of the motivational structure associated with the level of claims immediately advanced in the course of operations and is completed by students in the course of solving specific educational cognitive tasks through the use of the elearning platform Blackboard Learn for Academic Collaboration.

The examiner fixes in advance a certain stage during the exercises after the completion of which students must fill cards received earlier and continue their work on the assignments during the exercises in the course.

The main purpose of using the proposed questionnaire is to study and assess the level of motivation of students while they use the Blackboard Learn for Academic Collaboration e-learning platform and to track and differentiate the attitudes of students towards the use of the electronic platform and its functionalities in course training where the experiment was conducted.

For the level of educational and cognitive motivation, during solving a specific task, by using the e-learning platform (Blackboard Learn for Academic Collaboration), there can be deduced, according to the degree of manifestation, a high, moderate or low level of student's response to success or failure, increase or decrease in the willingness to work on the task. In the first phase of our study, these two types of motivation were explored for a target group including students majoring in physical education and in sports.

The second phase of our inquiry covers education majors' opinion on the educational platform functionalities demonstrates the same tendencies and confirms the 
conclusions made in that study. The result analysis at the beginning of the implementation of the mixed training project (with a duration of 15 weeks) on a specific subject from the curriculum, shows a very low level of students' academic motivation. According to the statistic information obtained after data processing, $27 \%$ of students claim to have no academic motivation at all, $47 \%$ of students admit to have weak motivation, for $19 \%$ of the students the level of motivation is moderate and only $7 \%$ claim to have strong motivation for academic learning. At the end of the experimental training the levels of motivation changes as follows: $42 \%$ of students claim to have strong motivation, for $46 \%$ the level of motivation is moderate, and only $12 \%$ admit still to have weak motivation for academic learning. The dynamics of different levels of students' motivation is obvious. It is a result of systematic use of electronic platforms in the context of a mixed educational model, combining electronic and traditional training of pedagogy students.

Students, involved in the experimental training, have been asked to share their expectations about such a mixed educational model on the basis of its different components related to the principles of collectivism and constructivism as educational paradigms on one hand, and on the other hand related to the technological aspects of offline and online media, synchronous and asynchronous communication and their educational potential.

According to the results, students' expectations refer to a great extend to the easy and fast access to various study materials. For $25 \%$ of students the best advantage of the mixed model is the electronic access to course lectures in a document format, $65 \%$ give priority to online lectures within the electronic environment, $26 \%$ would appreciate access to sample tests as separate files to download, for $75 \%$ of students a variety of interactive tests will support best their study. $83 \%$ of students expect to be able to find and download PowerPoint presentations on different topics. Different types of interactive teaching and learning materials are important for $70 \%$ of the students. A vast majority of $86 \%$ claims that the access to all kinds of virtual models, training experiments, or video and animation models and simulations are crucial for the successful study. $79 \%$ of the students will take advantage if they are offered links to extra Internet resources in both Bulgarian and foreign sites. The results also emphasize on searching for different ways to facilitate and improve communication between students and instructors; on an easy access to information about different extracurricular activities; up-to-date information about course requirements and assessment procedures; electronic portfolio implementation, supporting exams preparation.

There are some contradictory students' views about the mixed - electronic and traditional training model as a type of training that offers only mechanical connection with low social and academic value. An important aspect, when it comes to planning and implementing such a model of mixed electronic and traditional training, is students' opinion on the social value of their communication with instructors and professors. Even when it comes to education, students strongly prefer the popular social networks such as Facebook, Twitter, App.net, Linkedin to contact and communicate with the instructors ( $89 \%$ of the students involved), instead of the specialized platforms for electronic and distant learning. The face-to-face communication is not excluded from students' answers. On the contrary, students find it important to integrate 
successfully both electronic and face-to-face communication to achieve best educational results.

Another important factor that gives a priority to the mixed model of training and improves students' motivation is the opportunity to publicize and popularize students' works and achievements throughout the electronic platforms of education. Even when the publicity is within a given platform or group, it affects positively the levels of motivation. The increasing number of registered users who visit a student's portfolio or read a certain presentation affects to a great extent the quality of the implementation of the next task of the same student.

To illustrate this process, a research study has been done regarding students' preferences on the basic functionalities of the platform (Figure 1).

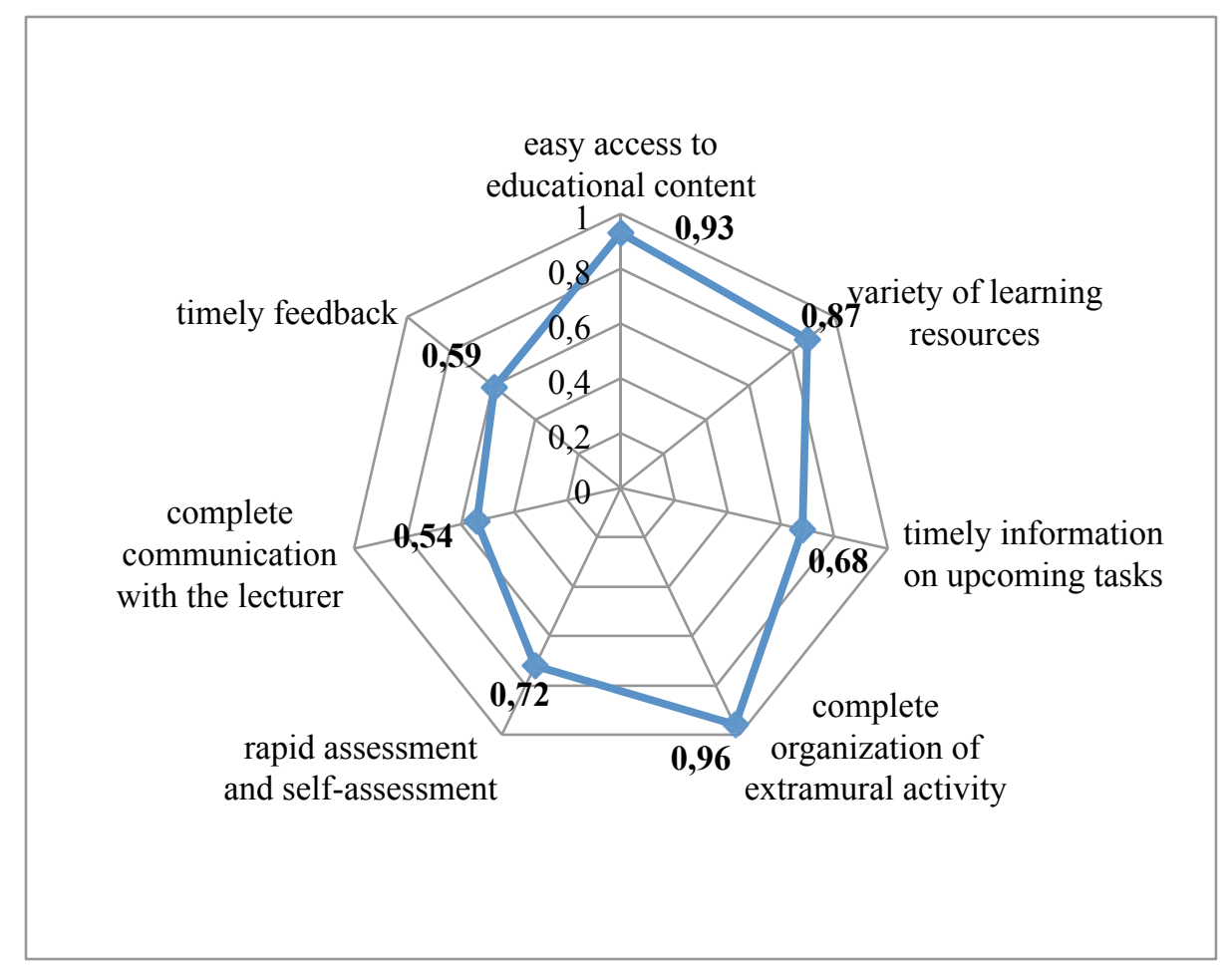

Fig. 1. Factor analysis on main functionalities of the platform

The results regarding the level of motivation in the course of using the electronic platform Blackboard Learn for Academic Collaboration are statistically significant and give a good idea of the impact of technology on the motivation for achievement, which is crucial to the overall educational and cognitive motivation. Although the study of motivation is a very complex process involving various factors that guide, regulate and maintain individual actions in the learning process, examining it in the course of using the electronic platform enables us to make conclusions about the attitude of students towards the activities and their results. 
In order to establish a correlation between success in solving the task and the level of motivation a chi-squared test $\left(\chi^{2}\right.$ test) is applied, since empirical data are represented by variables of two scales - ordinal (success) and nominal (level of motivation, which is characterized as mainly qualitative). If the null hypothesis $\left(H_{0}\right)$ states that between the success rate of students in the application of e-learning platform and the level of motivation for excellence, there is no logical connection, then the alternative hypothesis states that such a relationship exists. The empirical characterization of the hypothesis is $\chi_{e m p}^{2}=6.92$, while $\chi_{t}^{2}=5.86(\alpha=0.05)$. Comparing the theoretical to the empirical characterization of the hypothesis namely $\chi_{e m p}^{2}>\chi_{t}^{2}(6.92>5.86)$, gives us reason to reject the null hypothesis in favor to the alternative one, which means that there is a logical connection between success in using the e-learning platform and the level of motivation for achievement.

Factor analysis has been performed on the basis of the conversion of the set of correlating data in a new set of non-correlating variables (or factors) that explain the highest possible fraction of the total variation of the output data, thereby reducing the number of input variables by grouping those which correlate with each other in a common factor and separating uncorrelated ones at different factors.

\section{Conclusions}

When experimenting with educational techniques and technologies in university education, priority is given to new information and communication networks. The principle of their selection will be determined by the ability not just to know electronic platforms, resources and formats activity but primarily by the personal expectations and attitudes of students determined by the motives for purposeful behavior in training.

The survey results give reason to appreciate the dynamics of educational activity and its relation to motivation as a process. In this sense, blended learning is a new opportunity to establish priorities for studies related to the idea of innovative models of interaction between classical education and e-learning, stimulating a motivational mode of behavior in students' learning according to the functionalities of the selected electronic platform. The general conclusion that can be drawn here is the idea that the connection between the mixed model of education and students' motivation helps to focus the effort to improve students' academic behaviour and performance. It is well known that motivation is a result of personal inner needs and outer stimuli. It can be best explained by the ideas and principles of the competence approach, where the personal characteristics and skills development are tightly related. The mixed model of electronic and traditional training can be seen as an alternative of the competence approach. Being a regulative factor in human's behaviour, motivation creates the right conditions to concentrate students' attention on the most valuable aspects of learning. The idea of blended education at university gives opportunities to search and find new configuration of gnoseological, axiological and didactic factors irradiating a new concept of educational environment. 


\section{$5 \quad$ References}

[1] Peytcheva-Forsyth, R. \& Yovkova, B. (2015). How Students' Experience in E-Learning Affects Their Judgements about the Quality of an Online Course, International Journal of Human Capital and Information Technology Professionals (IJHCITP), 6(1), https://doi.org/10.4018/ijhcitp.2015010102

[2] Paechter, M., Maier, B. \& Macher D. (2010). Students' expectations of, and experiences in e-learning: Their relation to learning achievements and course satisfaction, Computers \& Education, 54, 222-229, https://doi.org/10.1016/j.compedu.2009.08.005

[3] Wu, J., Tennyson, R. \& Hsia, Tz. (2010). A study of student satisfaction in a blended elearning system environment, Computers \& Education, 55 155-164, https://doi.org/10.1016/j.compedu.2009.12.012

[4] Hoehn, J. \& Rietsch, P. (2008). Guide on Development and Implementation of Blended Learning. B-learning4all project, funded by the European Commission DG Education and Culture. Leonardo Da Vinci Programme.

[5] European Parliament and the Council (2006). Recommendation of the European Parliament and of the Council of 18 December 2006 on key competences for lifelong learning. Official Journal of the European Union, L394/310

[6] Balin, V., Gayda, V., Gerbachevski, V., et al. (2000). Workshop on common, experimental and applied psychology, Peter Publishing House, 306-308 (in Russian)

\section{Authors}

Nikolay Tsankov has a master's degree in Theory and methodology of teaching chemistry and physics and he holds a doctor's degree in Education. His professional and scientific research interests are in the fields of: theories of instruction, school didactics, theories of education, information theories in education, cognitive modelling in education, competence-based approach in education, competence for modelling, motivation in education, audio-visual and information technologies in education.

Ivo Damyanov has a master's degree in Mathematics and he holds a doctor's degree in Computer science. He is an assistant professor at the Department of Informatics. His professional and scientific research interests are in the fields of: metaprogramming, domain-specific languages and code generation, discrete functions, elearning and distance learning.

This paper is a revised and extended version of the article Students' preferences on basic functionality of e-learning platforms in the context of blended learning, published in Technics Technologies Education Management Journal, Volume 12, Number 1. Article submitted 01 April 2017. Published as resubmitted by the authors 10 May 2017. 